\title{
First-Phase Insulin and Amylin after Bariatric Surgery: A Prospective Randomized Trial on Patients with Insulin Resistance or Diabetes after Gastric Bypass or Sleeve Gastrectomy
}

\author{
Rahel Nussbaumera,b Anne Christin Meyer-Gerspach ${ }^{a, c}$ Ralph Peterlia, b \\ Thomas Peters $^{d}$ Christoph Beglinger ${ }^{a}$ Sonja Chiappetta ${ }^{e}$ \\ Juergen Drewe ${ }^{f}$ Bettina Wölnerhanssen ${ }^{a, c}$ \\ a University of Basel, Basel, Switzerland; ${ }^{b}$ Clarunis, Department of Visceral Surgery, \\ University Centre for Gastrointestinal and Liver Diseases, St. Claraspital and University \\ Hospital, Basel, Switzerland; ' 'St. Clara Research Ltd., St. Claraspital, Basel, Switzerland;

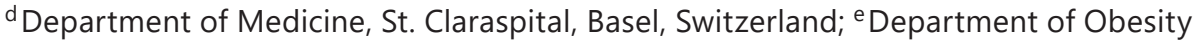 \\ and Metabolic Surgery, Ospedale Evangelico Betania, Naples, Italy; ${ }^{\mathrm{f} D e p a r t m e n t ~ o f ~}$ \\ Pharmacology and Toxicology, University Hospital, Basel, Switzerland
}

\section{Keywords}

First-phase insulin · $\beta$-Cell function - Bariatric surgery · Intravenous glucose stimulation *

Intravenous arginine stimulation

\begin{abstract}
Background: Most patients with severe obesity show glucose intolerance. Early after sleeve gastrectomy (LSG) or gastric bypass (LRYGB), a marked amelioration in glycemic control occurs. The underlying mechanism is not yet clear. Objective: To determine whether the improvement in glycemic control on the level of endocrine pancreatic function is due to an increased first-phase insulin secretion comparing LRYGB to LSG. Setting: University of Basel Hospital and St. Clara Research Ltd., Basel, Switzerland. Methods: Sixteen morbidly obese patients with severe obesity and different degrees of insulin resistance were randomized to LSG or LRYGB, and islet cell functions were tested by intravenous glucose and intravenous arginine administration before and 4 weeks after surgery. Results: Fasting insulin and glucose levels and homeostasis model assessment insulin resistance were significantly lower in both groups after surgery compared to baseline, while no change was seen in fasting C-peptide, amylin, and glucagon. After intravenous glucose stimulation, no statistically significant pre- to postoperative change in area under the curve (AUC 0-60 min) was seen for insulin, glucagon, amylin, and C-peptide. No statistically significant pre- to postoperative change in incremental
\end{abstract}


AUC for first-phase insulin release (AUC 0-10 min), second-phase insulin secretion (AUC 10-60 $\mathrm{min}$ ), and insulin/glucose ratio could be shown in either group. Arginine-stimulated insulin and glucagon release showed no pre- to postoperative change. Conclusion: Intravenous glucose and arginine administrations show no pre- to postoperative changes of insulin release, amylin, glucagon, or C-peptide concentrations, and no differences between LRYGB and LSG were found. The postoperative improvement in glycemic control is not caused by changes in endocrine pancreatic hormone secretion.

(C) 2020 The Author(s)

Published by S. Karger AG, Basel

\section{Introduction}

A high percentage of patients with severe obesity show glucose intolerance or insulin resistance with increased fasting insulin and glucose [1]. The main pathophysiological defect responsible for the development of type 2 diabetes is a combination of $\beta$-cell dysfunction with insulin resistance. $\beta$-Cell function in type 2 diabetes progressively declines, starting with a simple reduction to the total disappearance of the first phase (0-10 min) of glucose-induced insulin secretion, followed by impairment of the second-phase insulin secretion (10-60 min) [2,3]. First-phase insulin secretion disappears, even in the early stages of the disease, when fasting glucose concentrations are only slightly higher than normal [4]. This defect is important because first-phase insulin secretion seems to have the greatest impact on postprandial plasma glucose excursions, determining postmeal hyperglycemia [5]. Amylin is cosecreted with insulin by pancreatic $\beta$-cells, and plasma concentration increases in response to oral glucose intake. This peptide contributes to glycemic control by shutting down gluconeogenesis and plays a role in the control of food intake and satiation [6]. Amylin release in response to oral glucose intake is higher in patients with obesity and diabetes as these patients show an amylin resistance [7, 8]. Amylin synergizes leptin and peptide YY signaling, leading to increased satiation, reduced food intake and body weight in obese rat models and in humans [9-11]. During posttranslational modification of the insulin prohormone, the interconnecting C-peptide is cleaved and is therefore released at equimolar concentrations to insulin. Measuring C-peptide levels can give valuable information in regard to $\beta$-cell function. C-peptide seems also biologically active and plays a role in microvascular complications associated with diabetes [12]. As the counterplayer of insulin, glucagon is released by pancreatic $\alpha$-cells in response to hypoglycemia and promotes gluconeogenesis. Furthermore, glucagon and insulin are released in response to amino acids such as arginine.

The aim of this prospective, randomized study was to determine whether theimprovement in glycemic control in patients with severe obesity 4 weeks after laparoscopic Roux-en-Y gastric bypass (LRYGB) or laparoscopic sleeve gastrectomy (LSG) is related to an increased first-phase insulin secretion and to compare the 2 intervention types.

\section{Methods}

The protocol was approved by the Ethics Committee of Basel, Switzerland (EKBB: 08/11) and conducted in accordance with the principles of the Declaration of Helsinki. The trial is registered in the Clinical trials registry of the National Institutes of Health (NCT 00356213) and was funded by the Swiss National Science Foundation (grant No. 116 465). The patient group studied in this trial stems from a cohort of 217 patients who participated in a prospective randomized multicenter study comparing LSG to LRYGB [13]. Patients were evaluated by a 
multidisciplinary team and were included in the study if they fulfilled the criteria for bariatric surgery in Switzerland (body mass index [BMI] $>40$ or $>35$ with the presence of at least 1 comorbidity, aged between 18 and 65 years, and failure of conservative treatment over 2 years) and gave written informed consent. A subpopulation of 16 patients with severe obesity and insulin resistance from the above-mentioned cohort ( 9 females and 7 males; mean BMI $43.5 \pm 0.9$, mean age $45.8 \pm 3.0$ years) agreed to participate in this trial; 8 were randomized to LSG, 8 to LRYGB. Ten patients had advanced insulin resistance (homeostasis model assessment, HOMA, index range: 5.7-15.1), but were not on oral antidiabetic drugs yet (5 LSG and 5 LRYGB), and 6 patients (3 LSG and 3 LRYGB; HOMA index range: 10.5-19.2) were treated with oral antidiabetic drugs.

\section{Study Design}

The study was conducted as a randomized, prospective, parallel group trial. For intravenous stimulation studies, subjects were admitted to the Clinical Research Centre before and 1 month after the operation. On each occasion, an overnight fast of at least $10 \mathrm{~h}$ preceded the insertion of 2 antecubital vein catheters, one for blood collection, the second for infusion of secretagogues. After taking the fasting samples an intravenous bolus of glucose $(0.1 \mathrm{~g} / \mathrm{kg})$ was administered over $20 \mathrm{~s}$. Blood was collected at 2, 3, 5, 7.5, 10, 15, 30, 45, and $60 \mathrm{~min}$, and samples were processed for measurement of plasma insulin, glucose, amylin, and C-peptide concentrations. At $65 \mathrm{~min}, 2.5 \mathrm{~g}$ of arginine was injected intravenously over $120 \mathrm{~s}$. Blood was then taken at $67,68,70,72.5,75,80,95$, and $120 \mathrm{~min}$, and samples were processed for measurement of plasma levels of insulin, glucose, amylin, and glucagon. First-phase release of insulin was defined as $0-10 \mathrm{~min}$ after intravenous administration of glucose, second-phase release of insulin was defined as 10-60 min after administration.

\section{Plasma Glucose and Hormones}

Plasma glucose concentration was measured by a commercially available glucose oxidase method (Bayer Consumer Care AG, Switzerland). Insulin and glucagon were measured with a commercial radioimmunoassay (CISbio International, France). Amylin was measured with a commercially available ELISA kit (Millipore Inc., Billerica, MA, USA). C-peptide was measured with a commercially available radioimmunoassay kit (Millipore Corp., Billerica, MA, USA). HOMA insulin resistance was calculated by use of the fasting insulin-glucose product divided by the constant 22.5 [14]. Methods applied have been described previously in more detail [1, 15].

\section{Surgical Procedure}

The LRYGB technique included a small gastric pouch with a $25-\mathrm{mm}$ circular pouch jejunostomy to a $150-\mathrm{cm}$ antecolic Roux limb and an exclusion of $50 \mathrm{~cm}$ of biliopancreatic limb. The LSG was done along a 35-F bougie from the angle of His to approximately $3-4 \mathrm{~cm}$ orally to the pylorus.

\section{Statistical Analysis}

All statistical analysis was done using the statistical software package SPSS for Windows version 26.0 (SPSS, Chicago, IL, USA). Descriptive statistics were used for demographic variables such as age, weight, height, and BMI. Hormone and glucose profiles were analyzed by calculating pharmacodynamic parameters, that is, area under the concentration-time curve (AUC). Changes over time in patients' characteristics, fasting glucose, and hormone levels were assessed by general linear model analysis, including the factor "pre/post" for repeated within-subject measurements (before vs. 1 month after surgery) and "OP type" for the specific kind of surgery (LSG vs. LRYGB) as between-subject factor.

\section{Karger's}


In addition, to test for significant differences between pre- and postoperative findings for each OP type (e.g., LSG vs. LRYGB) values were compared using repeated measures ANOVA. To test for significant differences between different groups (LSG vs. LRYGB or patients with insulin resistance vs. patients with diabetes on antidiabetic drugs), the Student unpaired $t$ test was used. Values were reported as means \pm SEM. A $p$ value $<0.05$ was considered as statistically significant.

Table 1. Demographic characteristics and fasting glucose and hormone values of the study population

\begin{tabular}{|c|c|c|c|c|c|c|}
\hline & \multicolumn{2}{|l|}{ LRYGB } & \multicolumn{2}{|l|}{ LSG } & \multicolumn{2}{|l|}{ p values ${ }^{1}$} \\
\hline & $\begin{array}{l}\text { before } \\
\text { surgery }\end{array}$ & $\begin{array}{l}1 \text { month } \\
\text { after surgery }\end{array}$ & $\begin{array}{l}\text { before } \\
\text { surgery }\end{array}$ & $\begin{array}{l}1 \text { month } \\
\text { after surgery }\end{array}$ & pre/post & OP type \\
\hline Weight, kg & $135.5 \pm 6.4$ & $\begin{array}{l}124.0 \pm 6.0 \\
p<0.001^{2}\end{array}$ & $120.6 \pm 3.3$ & $\begin{array}{l}106.9 \pm 2.6 \\
p<0.001^{2}\end{array}$ & $<0.001$ & 0.034 \\
\hline BMI & $44.7 \pm 1.4$ & $\begin{array}{c}40.9 \pm 1.3 \\
p<0.001^{2}\end{array}$ & $42.4 \pm 0.8$ & $\begin{array}{c}37.6 \pm 1.0 \\
p<0.001^{2}\end{array}$ & $<0.001$ & 0.108 \\
\hline BMI loss, $\%$ & & $8.5 \pm 0.7$ & & $11.3 \pm 0.8$ & & $0.020^{3}$ \\
\hline Glucose, $\mathrm{mmol} / \mathrm{L}$ & $6.2 \pm 0.2$ & $\begin{array}{r}5.3 \pm 0.1 \\
p=0.003^{2}\end{array}$ & $6.4 \pm 0.6$ & $\begin{array}{l}5.4 \pm 0.3 \\
p=0.042^{2}\end{array}$ & $<0.001$ & 0.838 \\
\hline Insulin, $\mu \mathrm{U} / \mathrm{mL}$ & $45.9 \pm 4.2$ & $\begin{array}{c}30.8 \pm 5.0 \\
p=0.051^{2}\end{array}$ & $33.2 \pm 2.8$ & $\begin{array}{c}21.7 \pm 1.0 \\
p=0.006^{2}\end{array}$ & 0.002 & 0.011 \\
\hline HOMA-IR, $\mu \mathrm{U} / \mathrm{mL} \times \mathrm{mmol} / \mathrm{L}$ & $12.5 \pm 1.2$ & $\begin{array}{c}7.2 \pm 1.2 \\
p=0.022^{2}\end{array}$ & $9.7 \pm 1.6$ & $\begin{array}{c}5.2 \pm 0.4 ; \\
p=0.012^{2}\end{array}$ & 0.001 & 0.012 \\
\hline C-peptide ${ }^{4}, \mathrm{ng} / \mathrm{mL}$ & $3.1 \pm 0.5$ & $\begin{array}{r}3.4 \pm 0.4 \\
p=0.673^{2}\end{array}$ & $3.2 \pm 0.4$ & $\begin{array}{r}3.2 \pm 0.5 \\
p=0.941^{2}\end{array}$ & 0.751 & 0.948 \\
\hline Amylin, pmol/L & $20.1 \pm 2.6$ & $\begin{array}{c}16.4 \pm 1.1 \\
p=0.109^{2}\end{array}$ & $24.8 \pm 8.8$ & $\begin{array}{c}13.9 \pm 2.1 \\
p=0.156^{2}\end{array}$ & 0.061 & 0.845 \\
\hline Glucagon, pg/mL & $33.1 \pm 7.0$ & $\begin{array}{c}30.4 \pm 3.7 \\
p=0.696^{2}\end{array}$ & $31.0 \pm 4.6$ & $\begin{array}{c}24.5 \pm 3.0 \\
p=0.066^{2}\end{array}$ & 0.227 & 0.503 \\
\hline
\end{tabular}

Data are given as means \pm SEM. Statistically significant $p$ values are italicized. LSG, laparoscopic sleeve gastrectomy; LRYGB, laparoscopic Roux-en-Y gastric bypass; BMI, body mass index; HOMA-IR, homoeostasis model assessment insulin resistance. ${ }^{1} p$ values derived by general linear model analysis. ${ }^{2}$ For each OP type, pre/post comparison was done by repeated measures analysis of variance (after surgery vs. before surgery). ${ }^{3}$ Analysis of variance. ${ }^{4} \mathrm{C}$-peptide values are available in 7 subjects per group.

Fig. 1. Mean \pm SEM plasma glucose and insulin concentrations after intravenous glucose and intravenous arginine ( $0.1 \mathrm{~g} / \mathrm{kg}$ both) administration. a Glucose-stimulated glucose concentrations before OP. b Glucosestimulated glucose concentrations after OP. c Arginine-stimulated glucose concentrations before OP. d Arginine-stimulated glucose concentrations after OP. e Glucose-stimulated insulin concentrations before OP. f Glucose-stimulated insulin concentrations after OP. g Arginine-stimulated insulin concentrations before OP. h Arginine-stimulated insulin concentrations after OP.

(For figure see next page.) 

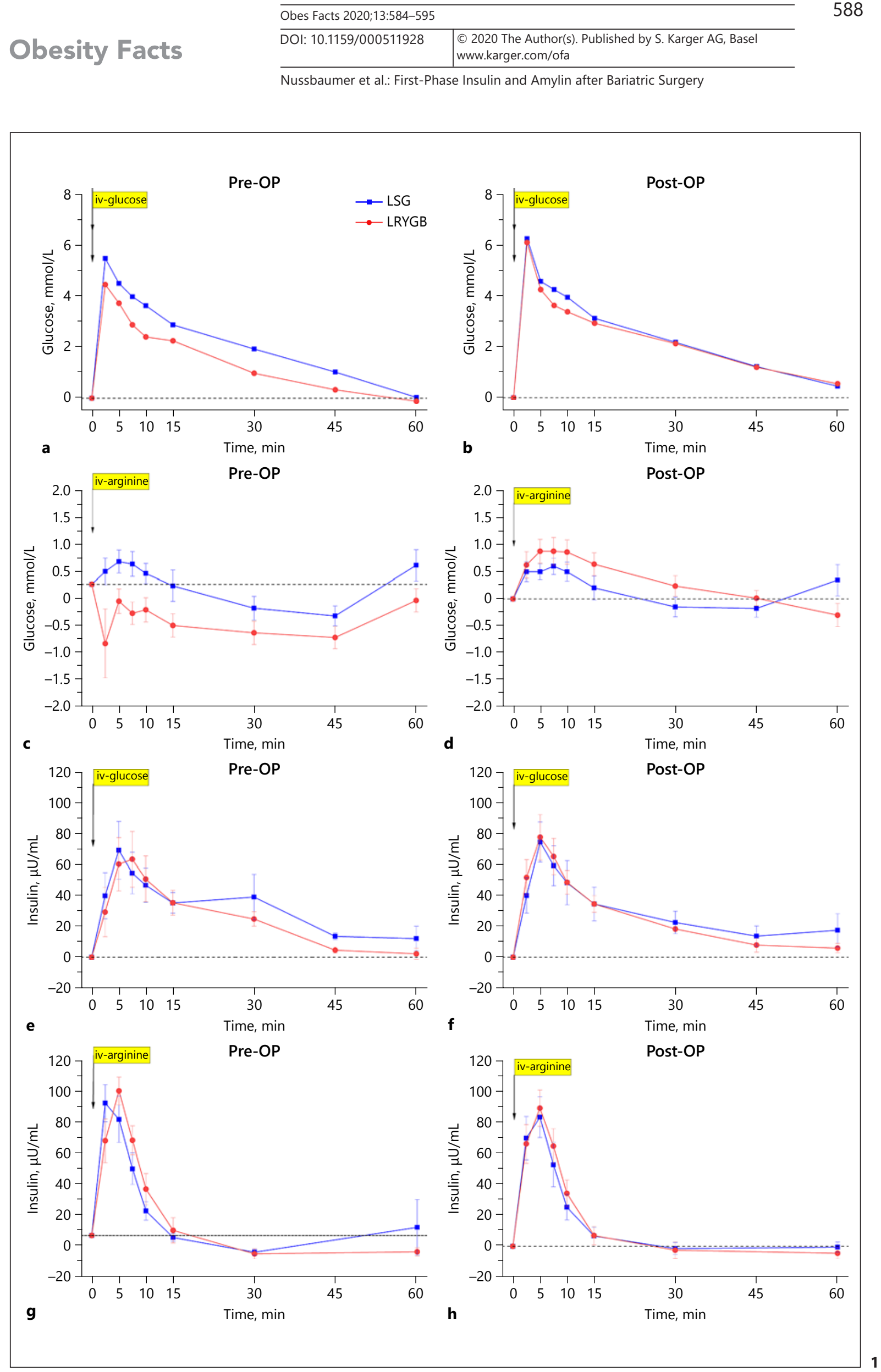

Karger's 


\section{Results}

Sixteen patients ( 9 females and 7 males) scheduled for bariatric surgery were seen in our outpatient clinic before and 4 weeks after surgery. Preoperative body weight was $128.1 \pm 4.0$ $\mathrm{kg}$ (range 107-163 kg), BMI $43.5 \pm 0.9$ (range 39.3-52.6), age $45.8 \pm 3.0$ years (range 18-63 years). Thirteen patients had dyslipidemia, 12 had arterial hypertension, 6 patients had been diagnosed with diabetes and were on oral antidiabetic drugs, and 1 patient had a history of coronary heart disease (with stent application). Eight patients underwent LSG and 8 LRYGB. All procedures were successfully concluded laparoscopically with no perioperative complications. Weight, height, BMI, comorbidities, gender distribution, and age were not significantly different between the 2 groups preoperatively. Weight loss and BMI loss was higher in LSG compared to LRYGB in this trial. In the LSG group, weight loss was $13.7 \pm 1.3 \mathrm{~kg}$ and $11.5 \pm$ $1.0 \mathrm{~kg}$ in the LRYGB group ( $p=0.034$ ), and percent excessive BMI loss was $11.3 \pm 0.8 \%$ for LSG and $8.5 \pm 0.7 \%$ for LRYGB ( $p=0.020$; Table 1$)$.

Fasting Glucose and Hormone Values and HOMA Insulin Resistance

Preoperative fasting values of glucose, C-peptide, amylin, and glucagon were not significantly different between the groups, whereas fasting insulin was significantly higher in the LRYGB group compared to the LSG group (LRYG: $45.9 \pm 4.2$, LSG: $33.2 \pm 2.8, p=0.03$; Table 1). In both groups, postoperative fasting insulin and glucose levels were significantly lower compared to preoperative values, while fasting C-peptide, amylin, and glucagon did not show any statistically significant change. Postoperative fasting insulin values were still higher in the LRYGB group compared to the LSG group (LRYGB; $30.8 \pm 5$, LSG: $21.7 \pm 1.0$ ), but this was not statistically significant.

There was no statistically significant difference between the 2 groups concerning preoperative HOMA insulin resistance (LRYGB: $12.5 \pm 1.2 \mu \mathrm{U} / \mathrm{mL} \times \mathrm{mmol} / \mathrm{L}$ vs. LSG: $9.7 \pm 1.6 \mu \mathrm{U} /$ $\mathrm{mL} \times \mathrm{mmol} / \mathrm{L}, p=0.186$ ). Postoperatively HOMA insulin resistance decreased significantly in both groups with no statistically significant difference in postoperative reduction (delta) between the 2 groups (LRYGB: $5.3 \pm 1.8$ and LSG: $4.5 \pm 1.3, p=0.729$ ).

\section{Glucose Stimulation}

Figure 1 depicts glucose-stimulated insulin and glucose kinetics before and after the operation. There was no statistically significant pre- to postoperative change in incremental AUC for insulin (0-60 min), first-phase insulin release (AUC 0-10 min), and secondphase insulin secretion (AUC 10-60 min) in either group. No statistically significant difference between LSG and LRYGB concerning insulin secretion (AUC 0-60 min, AUC 0-10 min, AUC 10-60 min) could be shown. There was no statistically significant change in incremental AUC (0-60 min) for amylin and C-peptide in either group (Table 2, Fig. 2).

\section{Arginine Stimulation}

Arginine-stimulated glucagon release was similar in both groups, and there was no statistically significant pre- to postoperative change in incremental AUC 0-60 (Table 2, Fig. 1, 2). In the LRYGB group, incremental AUC 0-60 of arginine-stimulated insulin and glucose release were significantly higher postoperatively compared to baseline (628 \pm 272 vs. $250 \pm 248 \mu \mathrm{U} \times \mathrm{min} / \mathrm{mL}[p=0.045]$ and $21 \pm 11$ vs. $-50 \pm 12 \mathrm{mmol} \times \min / \mathrm{L}[p=0.011]$, respectively).

\section{Karger'₹}



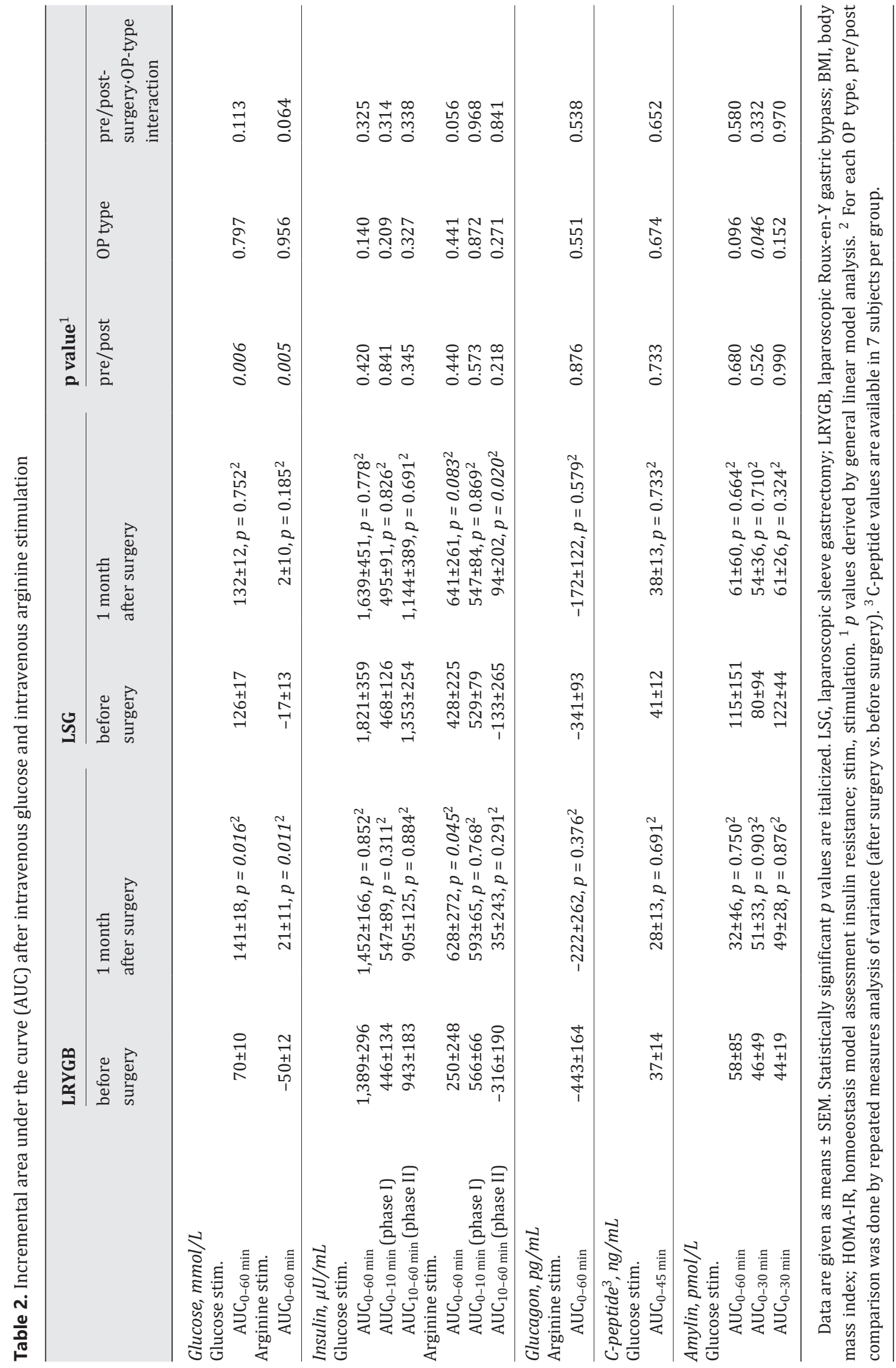


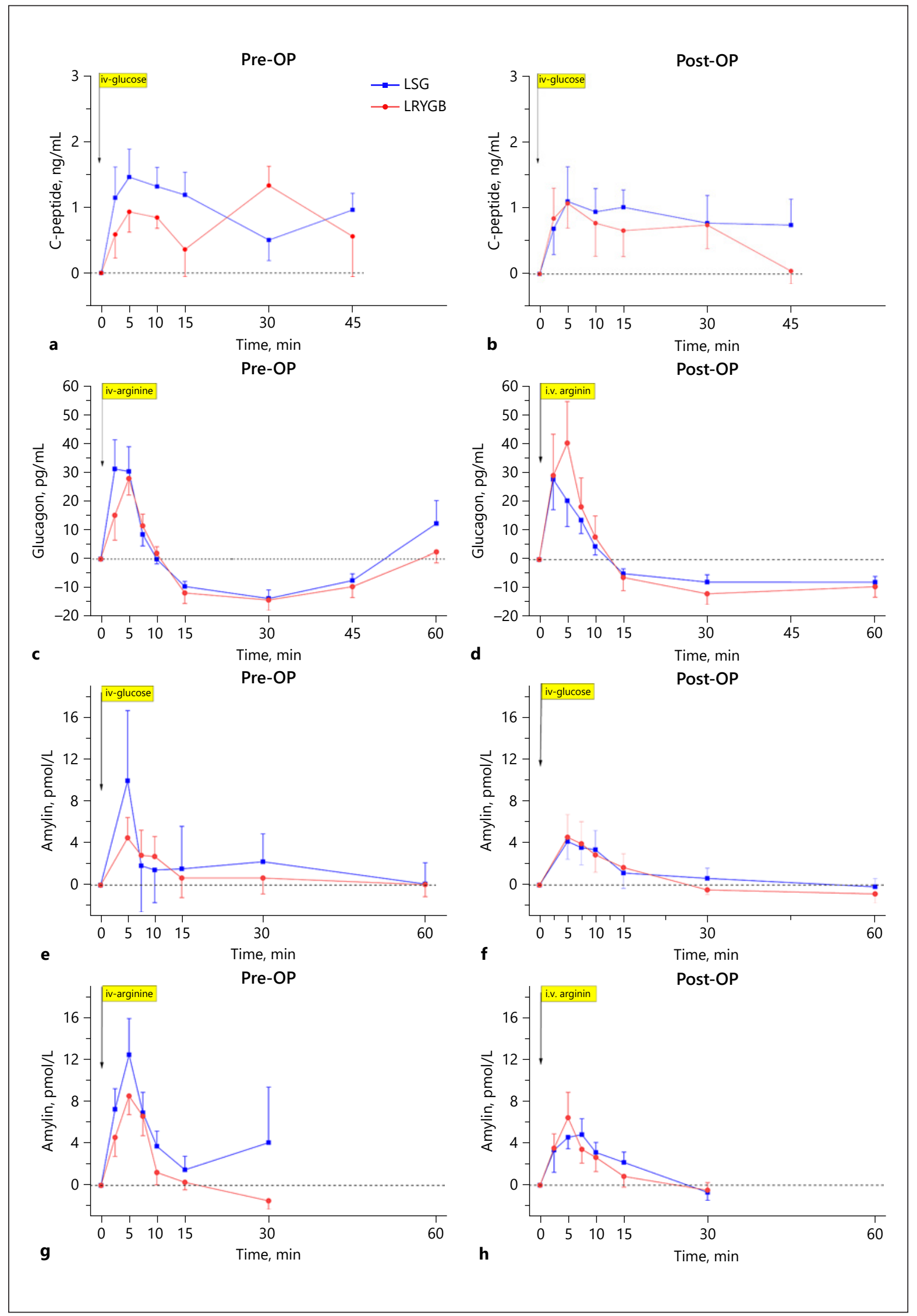


Nussbaumer et al.: First-Phase Insulin and Amylin after Bariatric Surgery

\section{Discussion}

This study aimed to analyze, whether intravenous glucose and intravenous arginine administration showed a different insulin and glucagon response after bariatric surgery, which would be explained by a restoration of $\beta$-cell function.

Bariatric surgery is a potent tool to improve glucose metabolism, a fact that has long been known [16,17]. In 1987, Pories et al. [16] reported that $99 \%$ of patients with severe obesity and type 2 diabetes or impaired glucose tolerance who had undergone Roux-en-Y gastric bypass (RYGB) became and remained euglycemic after surgery and reported that the patients were converted to euglycemia within 10 days, even if they had required large doses of insulin. Since then, different groups have confirmed and extended this observation $[2,18-20]$ by documenting that bariatric surgery is effective in improving and resolving type 2 diabetes. In a randomized, parallel group trial comparing LSG to LRYGB, we could show a marked amelioration in glycemic control within 8-10 days after either of the 2 procedures [1]. This unexpected result challenges previous hypotheses: it has been claimed that the normalization of insulin sensitivity that occurs very early after LRYGB before a significant weight loss occurs [18] may be dependent on the hormonal changes related to the nutrient diversion from the major part of the stomach, the duodenum, and approximately $50 \mathrm{~cm}$ of jejunum. In fact, the enteroendocrine cells are largely found in these tracts of the small intestine. Up to now 2 main hypotheses have been advanced to explain which part of the small intestine is implicated in the remission of diabetes. The first, known as the hindgut hypothesis [20-22], claims that diabetes control results from accelerated delivery of nutrients to the distal small intestine. The second, the so-called foregut hypothesis, states that the exclusion of duodenum and jejunum from nutrient transit might prevent the secretion of a (to date unknown) putative signal that promotes insulin resistance $[18,23,24]$. Our results did not support these conclusions: both LRYGB and LSG patients showed rapid improvement at an early, weight-independent stage and the benefit in glycemic control was similar after both operations [1,5], although neither fore- nor hindgut theory can really explain this effect for LSG. The mechanism leading to amelioration of glycemic control remains unclear.

Diabetes type 2 is generally regarded as a chronic, progressive disease, where impaired $\beta$-cell function cannot be cured, and only progression can be prevented. A reduced first-phase insulin response reflects impaired $\beta$-cell function and is impaired early in the development of diabetes. Patients with diabetes show a blunted curve rather than a clear peak, which is typically seen in the first 10 min after intravenous administration of glucose.

A study by Lim et al. [25] showed that mere diet restriction to $600 \mathrm{kcal} /$ day over a period of 8 weeks was able to increase first-phase insulin release in patients with diabetes, showing that at least early diabetes seems a reversible condition. In 2009, Salinari et al. [2] demonstrated that impaired first-phase insulin secretion in patients with severe obesity and diabetes was restored after biliopancreatic diversion, and in 2012 Basso et al. [26] observed the same phenomenon after LSG. The above-mentioned studies by Lim et al. [25] who showed that first-phase insulin release could be improved by caloric restriction of $600 \mathrm{kcal} /$ day alone raises questions to which extent the effect we see in our operated patients is due to fasting

Fig. 2. Mean \pm SEM plasma C-peptide, glucagon, and amylin concentrations after intravenous glucose and intravenous arginine ( $0.1 \mathrm{~g} / \mathrm{kg}$ both) administration. a Glucose-stimulated C-peptide concentrations before OP. b Glucose-stimulated C-peptide concentrations after OP. c Arginine-stimulated glucagon concentrations before OP. d Arginine-stimulated glucagon concentrations after OP. e Glucose-stimulated amylin concentrations before OP. f Glucose-stimulated amylin concentrations after OP. g Arginine-stimulated amylin concentrations before OP. $\mathbf{h}$ Arginine-stimulated amylin concentrations after OP.

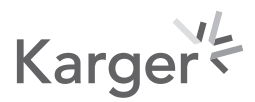


and caloric restriction and how much can be explained by weight-independent mechanisms, such as hormonal changes. Lim et al. [25] showed a slow increase in first-phase insulin over the course of 8 weeks, reaching almost normal values, whereas the improvement described by Basso et al. [26] was seen $72 \mathrm{~h}$ after surgery already. Four weeks after surgery as in our trial, improved glucose metabolism cannot be explained through weight loss alone. Also reduced calorie intake cannot explain the effect sufficiently. Our patients were fasting only up to 3 days after surgery and then went back to a diet with at least 1,000 kcal/day 4 weeks after surgery. In previous studies, our group could confirm postoperative changes on postprandial gut hormone release such as elevation of glucagon-like peptide-1, suppression of ghrelin, and restoration of dynamics [27], which are important for amelioration of glycemic control [28]. However, the so-called direct "incretin effect" (proportion of insulin being released as a consequence of gut hormone stimulation) can be ruled out in this study, as glucose was given intravenously. Amelioration of $\beta$-cell function (reflected by improved first-phase insulin release) after bariatric surgery could be shown by Salinari et al. [2], and findings by Basso et al. [26] confirm these results where a subgroup of patients with diabetes, who had the disease $\leq 10$ years, underwent an LSG procedure, and first-phase insulin secretion was restored. In our mixed group of patients with advanced insulin resistance or diabetes, first-phase insulin was not clearly impaired preoperatively, and 4 weeks postoperatively first-phase insulin remained unchanged in all patients. It seems that in our cohort, $\beta$-cell function was still intact and able to compensate for insulin resistance. This explains why HOMA decreased, while no change in first-phase insulin was seen.

While long-term favorable effects on glucose homeostasis after bariatric surgery might be due to a combination of weight loss, decrease in pancreatic and hepatic lipotoxicity, improved inflammatory status, and changes in gastrointestinal hormones (such as elevation of glucagon-like peptide-1, decrease in ghrelin), the mechanisms underlying short-term effects remain unclear.

Limitations

Although patients were randomized to LSG and LRYGB, surprisingly in this trial glucose excursions were lower in LRYGB compared to LSG patients before surgery. However, the preversus postoperative changes were not different comparing the 2 groups.

\section{Conclusions}

In a mixed group of patients with severe obesity and advanced insulin resistance or diabetes, intact first-phase insulin release was found. In contrast, patients exhibited insulin resistance (elevated fasting insulin and glucose values), which improved after surgery (HOMA index decreased). No difference was seen between LSG and LRYGB regarding amelioration of glucose homeostasis on $\beta$-cell level.

\section{Acknowledgments}

We would like to thank Ms. Claudia Bläsi and Ms. Luisa Baselgia for technical assistance. 


\section{Statement of Ethics}

Informed consent was obtained from all the individual participants included in the study. All procedures performed in this study involving human participants were conducted in accordance with the principles of the 1964 Declaration of Helsinki and its later amendments or comparable ethical standards. The protocol was approved by the Ethics Committee of Basel, Switzerland (EKBB: 08/11).

\section{Conflict of Interest Statement}

All authors have no conflicts of interest or financial ties to disclose.

\section{Author Contributions}

C.B., J.D., A.C.M.G., R.P., and B.W.: study conception and design; A.C.M.G., R.N., and B.W.: acquisition of data; C.B., J.D., A.C.M.G., R.N., R.P., T.P., S.C., and B.W.: analysis and interpretation of data; C.B., A.C.M.G., R.N., S.C., and B.W.: drafting of manuscript; C.B., J.D., A.C.M.G., S.C., and B.W.: critical revision.

\section{References}

1 Peterli R, Wölnerhanssen B, Peters T, Devaux N, Kern B, Christoffel-Courtin C, et al. Improvement in glucose metabolism after bariatric surgery: comparison of laparoscopic Roux-en-Y gastric bypass and laparoscopic sleeve gastrectomy: a prospective randomized trial. Ann Surg. 2009 Aug;250(2):234-41.

2 Salinari S, Bertuzzi A, Asnaghi S, Guidone C, Manco M, Mingrone G. First-phase insulin secretion restoration and differential response to glucose load depending on the route of administration in type 2 diabetic subjects after bariatric surgery. Diabetes Care. 2009 Mar;32(3):375-80.

3 Gerich JE. Contributions of insulin-resistance and insulin-secretory defects to the pathogenesis of type 2 diabetes mellitus. Mayo Clin Proc. 2003 Apr;78(4):447-56.

4 Gerich JE. Is reduced first-phase insulin release the earliest detectable abnormality in individuals destined to develop type 2 diabetes? Diabetes. 2002 Feb;51(Suppl 1):S117-21.

5 Bruce DG, Chisholm DJ, Storlien LH, Kraegen EW. Physiological importance of deficiency in early prandial insulin secretion in non-insulin-dependent diabetes. Diabetes. 1988 Jun;37(6):736-44.

6 Lutz TA. Control of energy homeostasis by amylin. Cell Mol Life Sci. 2012 Jun;69(12):1947-65.

7 Hartter E, Svoboda T, Ludvik B, Schuller M, Lell B, Kuenburg E, et al. Basal and stimulated plasma levels of pancreatic amylin indicate its co-secretion with insulin in humans. Diabetologia. 1991 Jan;34(1):52-4.

8 Thomaseth K, Pacini G, Clodi M, Kautzky-Willer A, Nolan JJ, Prager R, et al. Amylin release during oral glucose tolerance test. Diabet Med. 1997 Jun;14(Suppl 2):S29-34.

9 Trevaskis JL, Coffey T, Cole R, Lei C, Wittmer C, Walsh B, et al. Amylin-mediated restoration of leptin responsiveness in diet-induced obesity: magnitude and mechanisms. Endocrinology. 2008 Nov;149(11):5679-87.

10 Roth JD, Coffey T, Jodka CM, Maier H, Athanacio JR, Mack CM, et al. Combination therapy with amylin and peptide YY[3-36] in obese rodents: anorexigenic synergy and weight loss additivity. Endocrinology. 2007 Dec; 148(12):6054-61.

11 Roth JD, Roland BL, Cole RL, Trevaskis JL, Weyer C, Koda JE, et al. Leptin responsiveness restored by amylin agonism in diet-induced obesity: evidence from nonclinical and clinical studies. Proc Natl Acad Sci USA. 2008 May;105(20):7257-62.

12 Wahren J, Ekberg K, Samnegård B, Johansson BL. C-peptide: a new potential in the treatment of diabetic nephropathy. Curr Diab Rep. 2001 Dec;1(3):261-6.

13 Peterli R, Wölnerhanssen BK, Peters T, Vetter D, Kröll D, Borbély Y, et al. Effect of Laparoscopic Sleeve Gastrectomy vs Laparoscopic Roux-en-Y Gastric Bypass on Weight Loss in Patients With Morbid Obesity: The SM-BOSS Randomized Clinical Trial. JAMA. 2018 Jan;319(3):255-65.

14 Matthews DR, Hosker JP, Rudenski AS, Naylor BA, Treacher DF, Turner RC. Homeostasis model assessment: insulin resistance and beta-cell function from fasting plasma glucose and insulin concentrations in man. Diabetologia. 1985 Jul;28(7):412-9. 
15 Gerspach AC, Steinert RE, Schönenberger L, Graber-Maier A, Beglinger C. The role of the gut sweet taste receptor in regulating GLP-1, PYY, and CCK release in humans. Am J Physiol Endocrinol Metab. 2011 Aug; 301(2):E317-25.

16 Pories WJ, Caro JF, Flickinger EG, Meelheim HD, Swanson MS. The control of diabetes mellitus (NIDDM) in the morbidly obese with the Greenville Gastric Bypass. Ann Surg. 1987 Sep;206(3):316-23.

17 Buchwald H, Estok R, Fahrbach K, Banel D, Jensen MD, Pories WJ, et al. Weight and type 2 diabetes after bariatric surgery: systematic review and meta-analysis. Am J Med. 2009 Mar;122(3):248-256.e5.

18 Guidone C, Manco M, Valera-Mora E, Iaconelli A, Gniuli D, Mari A, et al. Mechanisms of recovery from type 2 diabetes after malabsorptive bariatric surgery. Diabetes. 2006 Jul;55(7):2025-31.

19 Buchwald H, Avidor Y, Braunwald E, Jensen MD, Pories W, Fahrbach K, et al. Bariatric surgery: a systematic review and meta-analysis. JAMA. 2004 Oct;292(14):1724-37.

20 Strader AD, Vahl TP, Jandacek RJ, Woods SC, D'Alessio DA, Seeley RJ. Weight loss through ileal transposition is accompanied by increased ileal hormone secretion and synthesis in rats. Am J Physiol Endocrinol Metab. 2005 Feb;288(2):E447-53.

21 Cummings DE, Overduin J, Foster-Schubert KE, Carlson MJ. Role of the bypassed proximal intestine in the antidiabetic effects of bariatric surgery. Surg Obes Relat Dis. 2007 Mar-Apr;3(2):109-15.

22 Holst JJ. The physiology of glucagon-like peptide 1. Physiol Rev. 2007 Oct;87(4):1409-39.

23 Rubino F, Forgione A, Cummings DE, Vix M, Gnuli D, Mingrone G, et al. The mechanism of diabetes control after gastrointestinal bypass surgery reveals a role of the proximal small intestine in the pathophysiology of type 2 diabetes. Ann Surg. 2006 Nov;244(5):741-9.

24 Rubino F, Gagner M, Gentileschi P, Kini S, Fukuyama S, Feng J, et al. The early effect of the Roux-en-Y gastric bypass on hormones involved in body weight regulation and glucose metabolism. Ann Surg. 2004 Aug;240(2): 236-42.

25 Lim EL, Hollingsworth KG, Aribisala BS, Chen MJ, Mathers JC, Taylor R. Reversal of type 2 diabetes: normalisation of beta cell function in association with decreased pancreas and liver triacylglycerol. Diabetologia. 2011 Oct;54(10):2506-14.

26 Basso N, Capoccia D, Rizzello M, Abbatini F, Mariani P, Maglio C, et al. First-phase insulin secretion, insulin sensitivity, ghrelin, GLP-1, and PYY changes $72 \mathrm{~h}$ after sleeve gastrectomy in obese diabetic patients: the gastric hypothesis. Surg Endosc. 2011 Nov;25(11):3540-50.

27 Peterli R, Steinert RE, Woelnerhanssen B, Peters T, Christoffel-Courtin C, Gass M, et al. Metabolic and hormonal changes after laparoscopic Roux-en-Y gastric bypass and sleeve gastrectomy: a randomized, prospective trial. Obes Surg. 2012 May;22(5):740-8.

28 Woerle HJ, Carneiro L, Derani A, Göke B, Schirra J. The role of endogenous incretin secretion as amplifier of glucose-stimulated insulin secretion in healthy subjects and patients with type 2 diabetes. Diabetes. 2012 Sep; 61(9):2349-58.

\section{Karger's}

